\title{
Delayed gastric emptying after Pancreaticoduodenectomy: a propensity score-matched analysis and clinical Nomogram study
}

\author{
Xianlei Cai, Miaozun Zhang, Chao Liang, Yuan Xu and Weiming Yu ${ }^{*}(\mathbb{0}$
}

\begin{abstract}
Background: Delayed gastric emptying (DGE) is a common and frustrating complication of pancreaticoduodenectomy (PD). Studies suggest that surgical methods and other clinical characteristics may affect the occurrence of DGE. Nevertheless, the results of such studies are conflicting. The objective of this work was to perform a propensity score matching analysis to compare the differences between pylorus-preserving pancreaticoduodenectomy (PPPD) and pylorus-removing pancreaticoduodenectomy (PrPD) and to develop and validate a nomogram to predict the probability of severe DGE (SDGE).
\end{abstract}

Methods: This retrospective study enrolled patients who underwent PD at our institution from December 2009 to December 2018. Propensity score matching was applied at a ratio of 1:1 to compare PPPD and PrPD groups. We compared incidence of complications, DGE, lengths of hospital stay, hospitalization costs, and mortality. Univariate and multivariate logistic regression analysis were performed to identify potential risk factors of severe DGE. Finally, a nomogram was developed and validated to predict severe DGE.

Results: The PPPD group had a significantly higher rate of postoperative pancreatic fistula (29.9\% versus $17.4 \%, P<$ $0.05)$ and less blood loss $(463.7 \mathrm{ml}$ versus $694.9 \mathrm{ml}, P<0.05)$. After propensity score matching, the PPPD group had a significantly higher rate of postoperative DGE (19.2\% versus $3.8 \%, P<0.05)$, especially severe DGE (17.3\% versus $0 \%)$ than the PrPD group. There were no significant differences in terms of lengths of hospital stay, hospitalization costs or mortality between the groups. Surgical method, biliary leakage, abdominal infection, and diabetes were independent risk factors for SDGE. The nomogram predicted SDGE with a training C - index of 0.798 and a validation C - index of 0.721.

Conclusion: PPPD increases the risk of DGE than PrPD, especially SDGE. Our prediction nomogram gives good prediction of SDGE after pancreaticoduodenectomy.

Keywords: Pancreaticoduodenectomy, Delayed gastric emptying, Propensity score-matching, Nomogram

\footnotetext{
*Correspondence: yuweiming7601@163.com

Department of Gastrointestinal Surgery, Ningbo Medical Center Lihuili

Hospital, 57 Xingning Road, 315000 Ningbo, PR China
}

(c) The Author(s). 2020 Open Access This article is licensed under a Creative Commons Attribution 4.0 International License, which permits use, sharing, adaptation, distribution and reproduction in any medium or format, as long as you give appropriate credit to the original author(s) and the source, provide a link to the Creative Commons licence, and indicate if changes were made. The images or other third party material in this article are included in the article's Creative Commons licence, unless indicated otherwise in a credit line to the material. If material is not included in the article's Creative Commons licence and your intended use is not permitted by statutory regulation or exceeds the permitted use, you will need to obtain permission directly from the copyright holder. To view a copy of this licence, visit http://creativecommons.org/licenses/by/4.0/ The Creative Commons Public Domain Dedication waiver (http://creativecommons.org/publicdomain/zero/1.0/) applies to the data made available in this article, unless otherwise stated in a credit line to the data. 


\section{Background}

Pancreaticoduodenectomy (PD) is a common choice for treatment of benign lesions as well as malignant neoplasms in the periampullary region. The procedure includes a 30-40\% distal gastrectomy [1] known as the conventional pancreaticoduodenectomy (cPD). Modifications of cPD have been reported, including subtotal stomach-preserving pancreaticoduodenectomy and pylorus- resecting pancreaticoduodenectomy [2, 3]. These are referred to as pylorus-removing pancreaticoduodenectomy (PrPD). Pylorus-preserving pancreaticoduodenectomy (PPPD) was first described by Traverso and Longmire [4] in 1978 with the preservation of the entire stomach; the procedure reduced the incidence of bile reflux gastritis and improved nutritional status $[5,6]$. Nevertheless, delayed gastric emptying (DGE) became a common and frustrating complication after PPPD [7, 8]. Although DGE is not life threatening, it can prolong hospital stay and decrease the quality of life. Currently, debate continues as to which surgical procedure is superior.

Enhanced recovery after surgery (ERAS) pathways are used worldwide to optimize patient outcomes, shorten length of hospital stay and to reduce hospitalization costs $[9,10]$. DGE is a huge obstacle for ERAS without compromising the safety of patients undergoing PD. Some meta-analyses have been performed [11, 12]; however, regarding DGE, high heterogeneity was found among pooled studies, and the standard of DGE and study design were not uniform; Furthermore, there are no tools to predict DGE after pancreatoduodenectomy; A nomogram would be a good tool for this purpose.

To compare possibility of postoperative DGE between PrPD and PPPD, and to develop a nomogram to predict incidence of severe DGE, we conducted this study based on a single center cohort.

\section{Methods}

\section{Patient selection}

This retrospective comparative study was performed at Ningbo Medical Center Lihuili Hospital in Zhejiang Province, China. Patients with pancreatic or periampullary lesions were identified from electronic medical records between December 2009 and December 2018. Exclusion criteria were as follows (1) tumor invading stomach tissue or had suspected metastasis of peripyloric lymph nodes or distant metastasis; (2) severe comorbidities prolonging the length of hospital stay, including heart failure, respiratory disorders, liver cirrhosis and mental illnesses. Comorbidities of the cardiovascular and cerebrovascular systems, respiratory system or nervous system can affect recovery, interfere with the short-term effect of the procedure and introduce bias. Finally, a total of 308 consecutive patients who underwent PD were identified (67 patients underwent PPPD and 241 patients underwent PrPD). We recorded medical histories, lab values, perioperative characteristics, postoperative outcomes, complications and mortality.

\section{Surgical procedures}

Radical pancreatectomy and lymphadenectomy were performed for all patients by experienced surgeons. All the procedures were performed by Professor Caide $\mathrm{Lu}$ and his team. For PPPD, we divided the proximal duodenum 2 to $3 \mathrm{~cm}$ distal to the pylorus. For PrPD, the stomach was divided at 2 to $5 \mathrm{~cm}$ proximal to the pylorus. The surgical procedures were base the discretion of the surgeon rather than the extent of tumor or other factors. The peripyloric lymph nodes were also dissected in PPPD. Reconstruction was performed as follows: An end-to-side antecolic duodenojejunostomy in PPPD or gastrojejunostomy in PrPD was performed. An end-to-side pancreatojejunostomy or binding pancreaticogastrostomy [13] was chosen. An end-toside choledochojejunostomy was performed both in PPPD and PrPD. The gastric outlet diameter of the anastomotic stoma was measured and confirmed intra-operatively.

\section{Postoperative management}

All patients received proton pump inhibitor (PPI), prophylactic antibiotics, octreotide and nutritional support post-operatively. The nasogastric tube was removed within 3 days after the surgery according to the amount of drainage from the nasogastric tube. Oral fluid intake was started at the postoperative day 4-5 unless there were complications such as DGE. Other treatment would be given as indicated including prokinetic agents for abdominal discomfort and distention.

The consensus definition and clinical grading of DGE were proposed by the International Study Group of Pancreatic Surgery (ISGPS) [14]. DGE was classified into three categories (grades A, B and C) according to postoperative management, including the period of nasogastric tube required, reinsertion of nasogastric tube, the time of inability to tolerate oral intake of solids, vomiting / gastric distention or use of prokinetic agents [14]. Grades B and C usually required an adjustment of clinical management and was defined as severe DGE (SDGE). Other post-operative complications such as pancreatic fistula, intra-abdominal hemorrhage, and bile leakage were consistent with the definitions by the International Study Group [15-17].

\section{Propensity score matching}

We conducted propensity score matching to control for confounding biases to construct a randomized experiment-like situation [18, 19]. Propensity scores (PS) were estimated using a logistic regression model [20] in which patient characteristics were regarded as covariates. These included age, gender, presence of diabetes mellitus, pre-operative albumin 
level, pre-operative leukocyte counts, total bilirubin level, jaundice reduction therapy (i.e. pre-operative stenting, percutaneous transhepatic cholangial drainage (PTCD), and endoscopic nasobiliary drainage (ENBD)), anastomotic pattern of the pancreas (pancreaticogastrostomy or pancreatojejunostomy), operative time, blood loss, enteral nutrition, and complications. Surgical methods were regarded as the dependent variable. We determined the degree of overlap PS value and covariates between PPPD and PrPD groups using propensity score graph. We conducted 1:1 matching using the nearestneighbor method with a caliper of 0.02 to prevent bias from distant matches [21]. Balance between groups was defined as a $p$-value greater than 0.05 .

\section{Statistical analysis}

We compared the continuous variables using the Student t-test between PPPD and PrPD groups. The chisquare test or Fisher's exact tests were performed for categorical variables. Univariate and multivariate logistic regression analyses were performed to calculate the odds ratios (ORs) and their 95\% confidence intervals (CIs) for each risk factor for PPPD group with reference to the PrPD group. Inclusion and exclusion criteria of type I error $=0.10$ were set in the stepwise multivariate logistic regression analysis.

Discrimination that reflected the ability of a predictive model to distinguish events and non-events correctly was validated using the concordance index (c-index), that is, a generalization of the area under the receiver operating characteristic (ROC) curve. Model calibration was validated using calibration plots and the HosmerLemeshow method [22].

Propensity score matching was performed using STATA version 12.0 (StataCorp LP, College Station, TX, USA). Other statistical analyses were performed using IBM SPSS Statistics Software version 20.0 (IBM Corporation, Armonk, NY, USA) and R software for Windows, version 3.6.1. A $p$-value of $<0.05$ (two-sided) was considered statistically significant.

\section{Results}

\section{Patient characteristics}

A total of 308 patients who underwent PPPD or PrPD in our hospital were identified from the electronic medical records, of which 199 (64.6\%) were male and 109 (35.4\%) were female. The mean age was $62.2 \pm 11.5$ years. The mean length of hospital stays was $20.3 \pm 12.8$ days. The incidence of DGE was $17.5 \%$ (54/308). Among all patients, 67 (21.8\%) underwent PPPD and 241 (78.2\%) underwent PrPD. We selected 52 pairs after 1:1 propensity score matching. Table 1 displays patient characteristics in the unmatched and the propensity score matched groups. The demographics were similar in the two groups. Table 2 displays the peri-operative data from both groups. In the unmatched group, patients in the PPPD group were more likely to undergo binding pancreaticogastrostomy and had less intraoperative blood loss when compared with the PrPD group. After propensity score matching, patient distributions between PPPD group and PrPD group were balanced.

Comparison of Short-Term Effects Between PPPD and PrPD.

Table 3 displays the incidence of complications, length of hospital stays, hospitalization costs, the proportion of death, and the incidence of DGE and severe DGE (grade $\mathrm{B} / \mathrm{C}$ ) in both groups. In the unmatched groups, the patients who underwent PPPD had a higher incidence of postoperative pancreatic fistula $(29.9 \%$ versus $17.4 \%, p=$ 0.025 ), a shorter length of hospital stays (16.4 days versus 21.3 days, $p=0.004)$ and lower costs $(41,273.2 \mathrm{CNY}$ versus $48,869.8 \mathrm{CNY}, p=0.041$ ) than did those who underwent PrPD, but they had higher incidence of severe DGE $(17.9 \%$ versus $8.7 \%, p=0.031)$. After propensity score matching, there was no significant difference in length of hospital stay or hospitalization costs between the PPPD and PrPD groups. However, patients in the PPPD group had a significantly higher risk of DGE and severe DGE than did patients in the PrPD group $(p=$ 0.014 and $p=0.003$, respectively). Before propensity

Table 1 Characteristics of patients in unmatched group and the propensity score matched group

\begin{tabular}{|c|c|c|c|c|c|c|}
\hline \multirow[t]{2}{*}{ Parameter } & \multicolumn{3}{|c|}{ Before propensity matching } & \multicolumn{3}{|c|}{ After propensity matching } \\
\hline & $\begin{array}{l}\text { PPPD group } \\
(n=67)\end{array}$ & $\begin{array}{l}\text { PrPD group } \\
(n=241)\end{array}$ & $P$ value & $\begin{array}{l}\text { PPPD group } \\
(n=52)\end{array}$ & $\begin{array}{l}\text { PrPD group } \\
(n=52)\end{array}$ & $P$ value \\
\hline Age (years) & $62.4 \pm 13.0$ & $62.1 \pm 11.0$ & 0.868 & $63.1 \pm 13.2$ & $63.4 \pm 11.5$ & 0.893 \\
\hline Gender (male/female) & $37 / 30$ & $162 / 79$ & 0.069 & $30 / 22$ & $24 / 28$ & 0.326 \\
\hline Diabetes mellitus(\%) & $6(9)$ & $35(14.5)$ & 0.235 & $4(7.7)$ & $3(5.8)$ & 0.696 \\
\hline Albumin(g/dL) & $38.7 \pm 5.0$ & $38.6 \pm 4.8$ & 0.891 & $38.2 \pm 5.30$ & $39.2 \pm 5.07$ & 0.352 \\
\hline WBC(/L) & $6.4 \pm 2.1$ & $6.2 \pm 2.3$ & 0.595 & $6.25 \pm 2.14$ & $6.36 \pm 2.03$ & 0.797 \\
\hline TB (umol/L) & $88.9 \pm 96.0$ & $98.9 \pm 113.0$ & 0.514 & $96.1 \pm 98.9$ & $96.5 \pm 104.1$ & 0.982 \\
\hline Malignant tumor(\%) & $62(92.5)$ & 227(94.2) & 0.575 & $47(90.4)$ & $45(86.5)$ & 0.760 \\
\hline Jaundice reduced(\%) & $5(7.5)$ & $12(5)$ & 0.544 & $5(9.6)$ & $7(13.5)$ & 0.539 \\
\hline
\end{tabular}

WBC white blood cell, $T B$ total bilirubin 
Table 2 Operative factors of patients in unmatched group and the propensity score matched group

\begin{tabular}{|c|c|c|c|c|c|c|}
\hline \multirow[t]{2}{*}{ Parameter } & \multicolumn{3}{|c|}{ Before propensity matching } & \multicolumn{3}{|c|}{ After propensity matching } \\
\hline & $\begin{array}{l}\text { PPPD group } \\
(n=67)\end{array}$ & $\begin{array}{l}\text { PrPD group } \\
(n=241)\end{array}$ & $P$ value & $\begin{array}{l}\text { PPPD group } \\
(n=52)\end{array}$ & $\begin{array}{l}\text { PrPD group } \\
(n=52)\end{array}$ & $P$ value \\
\hline pancreaticogastrostomy (\%) & $55(82.1)$ & $122(50.6)$ & 0.000 & $42(80.8 \%)$ & $41(78.8 \%)$ & 0.807 \\
\hline Enteral nutrition(\%) & $9(13.4)$ & $41(17.0)$ & 0.482 & $9(17.3)$ & $9(17.3)$ & 1.000 \\
\hline Operation time (min) & $358.6 \pm 83.0$ & $377.6 \pm 90.0$ & 0.125 & $353.5 \pm 87.3$ & $344.0 \pm 56.8$ & 0.512 \\
\hline Blood loss (ml) & $463.7 \pm 236.3$ & $694.9 \pm 680.9$ & 0.012 & $471.7 \pm 245.0$ & $497.5 \pm 279.7$ & 0.618 \\
\hline
\end{tabular}

matching, we found the selection of anastomotic pattern of the pancreas was significantly different between the PPPD and PrPD groups. In order to reduce the interference of this situation, we also analyzed the association between the anastomotic pattern of the pancreas and other clinical characteristics. The results indicated that the anastomotic pattern of the pancreas was not associated with blood loss and postoperative pancreatic fistula $(p=0.918$ and $p=$ 0.450 , respectively; as shown in Supplementary Table 1).

\section{Risk factors for SDGE}

In the univariate logistic regression analysis, surgical method, biliary leakage pancreatic fistula, and abdominal infection were associated with postoperative SDGE. By contrast, age, gender, diabetes, albumin, anastomosis, bleeding, and operation time did not have significant effects. The significant risk factors determined in the univariate analysis and diabetes $(p=0.059)$ were used in a multivariate logistic regression analysis. We found that diabetes, surgical method, biliary leakage, and abdominal infection were significant independent risk factors for SDGE (Table 4).

\section{Development of clinical nomogram for SDGE}

All patients were randomly divided into two groups: a development set $(80 \%)$ and a validation set $(20 \%)$. Detailed baseline characteristics of the development and validation sets are displayed in Table 5. Based on the results of the multivariate logistic regression analysis, diabetes, surgical method, biliary leakage, and abdominal infection were used to develop a prediction model and to generate a nomogram predicting the probability of SDGE (Fig. 1). The predictive accuracies of the nomogram calculated using AUC were 0.798 (95\% CI: 0.708-0.887) (Fig. 2a) for the development set and 0.726 (95\% CI: 0.486-0.966) for the validation set (Supplementary Fig. 1A). The calibration plot using the Hosmer-Lemeshow test revealed good agreement between predicted probability and observed outcome for the development set $(p=0.98$, Fig. $2 b)$ and the validation set ( $p=0.99$, Supplementary Fig. 1B).

\section{Discussion}

The major findings of this study were that PPPD was significantly associated with an increased rate of postoperative DGE, especially severe DGE. There was no significant difference in length of hospital stay and hospitalization costs between PPPD and PrPD groups after adjustment for possible confounders. In addition to surgical method, biliary leakage, abdominal infection, and diabetes were also independent risk factors for SDGE. Moreover, We generated a nomogram and validated it to predict the probability of SDGE. For example,

Table 3 postoperative factors in unmatched group and the propensity score matched group

\begin{tabular}{|c|c|c|c|c|c|c|}
\hline \multirow[t]{2}{*}{ Parameter } & \multicolumn{3}{|c|}{ Before propensity matching } & \multicolumn{3}{|c|}{ After propensity matching } \\
\hline & $\begin{array}{l}\text { PPPD group } \\
(n=67)\end{array}$ & $\begin{array}{l}\text { PrPD group } \\
(n=241)\end{array}$ & $P$ value & $\begin{array}{l}\text { PPPD group } \\
(n=52)\end{array}$ & $\begin{array}{l}\text { PrPD group } \\
(n=52)\end{array}$ & $P$ value \\
\hline \multicolumn{7}{|l|}{ Complications(\%) } \\
\hline Pancreatic fistula & $20(29.9 \%)$ & $42(17.4 \%)$ & 0.025 & $13(25.0 \%)$ & $12(23.1 \%)$ & 0.819 \\
\hline Biliary leakage & $1(1.5 \%)$ & 19(7.9\%) & 0.088 & $0(0 \%)$ & $1(1.9 \%)$ & 0.315 \\
\hline Intra-abdominal infection & 19(28.4) & $58(24.1 \%)$ & 0.473 & 16(30.8\%) & $9(17.3 \%)$ & 0.108 \\
\hline Bleeding & $3(4.5 \%)$ & $7(2.9 \%)$ & 0.458 & $3(5.8 \%)$ & $1(1.9 \%)$ & 0.308 \\
\hline hospital stay (day) & $16.4 \pm 7.68$ & $21.3 \pm 13.7$ & 0.004 & $16.6 \pm 8.08$ & $18.5 \pm 9.95$ & 0.268 \\
\hline Cost (CNY) & $41,273.2 \pm 9915.1$ & $48,869.8 \pm 29,867.7$ & 0.041 & $41,273.2 \pm 9385$ & $49,443.6 \pm 34,212$ & 0.097 \\
\hline Death(\%) & $1(1.5 \%)$ & $4(1.7 \%)$ & 1.000 & $1(1.9 \%)$ & $1(1.9 \%)$ & 0.315 \\
\hline DGE(\%) & 13(19.4\%) & $41(17.0 \%)$ & 0.649 & 10(19.2\%) & $2(3.8 \%)$ & 0.014 \\
\hline Severe DGE & $12(17.9 \%)$ & $21(8.7 \%)$ & 0.031 & $9(17.3 \%)$ & $0(0 \%)$ & 0.003 \\
\hline
\end{tabular}


Table 4 Risk factors for SDGE according to Logistic regression model

\begin{tabular}{|c|c|c|c|c|c|c|c|}
\hline \multirow[t]{3}{*}{ Factors } & \multirow[t]{3}{*}{ Subgroup } & \multicolumn{6}{|c|}{ SDGE $(n=247)$} \\
\hline & & \multicolumn{3}{|c|}{ Univariate analysis } & \multicolumn{3}{|c|}{ Multivariate analysis } \\
\hline & & $\mathrm{HR}$ & $95 \% \mathrm{Cl}$ & $p$ & $\overline{\mathrm{HR}}$ & $95 \% \mathrm{Cl}$ & $p$ \\
\hline \multirow[t]{2}{*}{ Age } & $<60$ & 1 & & 0.901 & & & \\
\hline & $\geq 60$ & 0.95 & $0.43-2.12$ & & & & \\
\hline \multirow[t]{2}{*}{ Gender } & Female & 1 & & 0.320 & & & \\
\hline & Male & 1.55 & $0.65-3.71$ & & & & \\
\hline \multirow[t]{2}{*}{ Diabetes } & No & 1 & & 0.059 & 1 & & 0.045 \\
\hline & Yes & 2.50 & $0.97-6.47$ & & 3.00 & $1.03-8.78$ & \\
\hline \multirow[t]{2}{*}{ Albumin } & $<30$ & 1 & & 0.702 & & & \\
\hline & $\geq 30$ & 1.50 & $0.19-12.01$ & & & & \\
\hline \multirow[t]{2}{*}{ Surgery } & PrPD & 1 & & 0.010 & 1 & & 0.002 \\
\hline & PPPD & 3.00 & $1.30-6.95$ & & 4.78 & $1.78-12.86$ & \\
\hline \multirow[t]{2}{*}{ Anastomosis } & $\mathrm{PO}$ & 1 & & 0.150 & & & \\
\hline & $P G$ & 1.81 & $0.81-4.04$ & & & & \\
\hline \multirow{2}{*}{$\begin{array}{l}\text { Biliary } \\
\text { leakage }\end{array}$} & No & 1 & & 0.001 & 1 & & 0.002 \\
\hline & Yes & 6.07 & $2.15-17.15$ & & 7.01 & $2.07-23.78$ & \\
\hline \multirow{2}{*}{$\begin{array}{l}\text { Pancreatic } \\
\text { fistula }\end{array}$} & No & 1 & & 0.030 & 1 & & 0.542 \\
\hline & Yes & 2.57 & $1.10-6.02$ & & 0.71 & $0.24-2.11$ & \\
\hline \multirow[t]{2}{*}{ Bleeding } & No & 1 & & 0.359 & & & \\
\hline & Yes & 2.12 & $0.43-10.54$ & & & & \\
\hline \multirow{2}{*}{$\begin{array}{l}\text { Abdominal } \\
\text { infection }\end{array}$} & No & 1 & & 0.000 & 1 & & 0.004 \\
\hline & Yes & 4.82 & $2.10-11.04$ & & 4.32 & $1.61-11.59$ & \\
\hline \multirow{2}{*}{$\begin{array}{l}\text { Operation } \\
\text { time }\end{array}$} & $<6 h$ & 1 & & 0.643 & & & \\
\hline & $\geq 6 \mathrm{~h}$ & 1.63 & $0.21-13.00$ & & & & \\
\hline
\end{tabular}

a patient with diabetes (55 points) who underwent PPPD (79 points) had postoperative abdominal infection (70 points) but no biliary leakage (0 points). This patient had a total score of 204 points. The predicted probability of SDGE would be approximately $55 \%$.

DGE is one of the most common postoperative complications of pancreaticoduodenectomy. The reported incidence of DGE varied widely and remained controversial in various medical centers according to the definitions from ISGPS. In some studies [7, 23, 24], nearly one-third of patients suffered DGE after PD. In our study, the overall incidence of DGE was $17.5 \%$. Although DGE is not a life threatening complication, it causes severe discomfort and decreases the quality of life postoperatively; it is also considered to increase the length of hospital stay and hospital costs [1].

Several retrospective studies and some high-quality randomized controlled trials (RCTs) have been reported. An RCT by Kawai et al. [1] found that the incidence of DGE was significantly higher in the PPPD group than in the PrPD group (17.2\% versus $4.5 \%)$. Another RCT by Matsumoto et al. [2] showed that although the incidence of DGE in the PPPD group was higher than that of the PrPD group(20\% versus 12\%), the difference was not statistically significant. Two RCTs conducted by Seiler et al. [25] and Tran et al. [26] found that the classic Whipple procedure had no effect on reducing the incidence of DGE when compared with PPPD. However, the definition of DGE was not assessed according to the ISGPS. A retrospective study by Fujii et al. [27] showed that the incidence of DGE was significantly higher in the PPPD group (27.3\%) than in the PrPD group (5.4\%) and Nanashima et al. [28] found patients in PPPD group were more likely to have severe DGE. There have also been meta-analyses published recently. The metaanalysis by $\mathrm{Wu}$ et al. [11] included 27 studies involving 2599 patients; they found that PrPD reduced DGE incidence but increased blood loss when compared with PPPD, and the lengths of hospital stay were similar in the two groups. Another meta-analysis by Yang et al. [12] included eight RCTs with a total of 622 patients; they also presented similar results that the PPPD group had a higher rate of DGE $(\mathrm{RR}=2.35$, 95\% CI: 1.06-5.21). However, the most recent metaanalysis by Hanna et al. [8] found that there was no significant difference between PPPD and classic PD. Therefore, disputes still exist. 
Table 5 Baseline characteristics of the development and validation set

\begin{tabular}{|c|c|c|c|}
\hline Factors & Subgroup & $\begin{array}{l}\text { development set }(n=247) \\
\text { No of patient }(\%)\end{array}$ & $\begin{array}{l}\text { Validation set }(n=61) \\
\text { No of patient }(\%)\end{array}$ \\
\hline \multirow[t]{2}{*}{$\overline{\text { Age }}$} & $\geq 60$ & $140(56.7)$ & $18(29.5)$ \\
\hline & $<60$ & 107 (43.3) & $43(70.5)$ \\
\hline \multirow[t]{2}{*}{ Gender } & Male & $152(61.5)$ & $47(77.0)$ \\
\hline & Female & $95(38.5)$ & $14(23.0)$ \\
\hline \multirow[t]{2}{*}{ Diabetes } & Yes & $34(13.8)$ & $7(11.5)$ \\
\hline & No & $213(86.2)$ & $54(88.5)$ \\
\hline \multirow[t]{2}{*}{ Albumin } & $\geq 30$ & $234(94.7)$ & $60(98.4)$ \\
\hline & $<30$ & $13(5.3)$ & $1(1.6)$ \\
\hline \multirow[t]{2}{*}{ Surgery } & PPPD & $52(21.1)$ & 15 (24.6) \\
\hline & PrPD & 195 (78.9) & $46(75.4)$ \\
\hline \multirow[t]{2}{*}{ Anastomosis } & $P G$ & $142(57.5)$ & $35(57.4)$ \\
\hline & $\mathrm{PO}$ & $105(42.5)$ & $26(42.6)$ \\
\hline \multirow[t]{2}{*}{ Biliary leakage } & Yes & $19(7.7)$ & $1(1.6)$ \\
\hline & No & $228(92.3)$ & $60(98.4)$ \\
\hline \multirow[t]{2}{*}{ Pancreatic fistula } & Yes & $51(20.6)$ & $11(18.0)$ \\
\hline & No & $196(79.4)$ & $50(82.0)$ \\
\hline \multirow[t]{2}{*}{ Bleeding } & Yes & $10(4.0)$ & $0(0)$ \\
\hline & No & $237(96.0)$ & $61(100)$ \\
\hline \multirow{2}{*}{$\begin{array}{l}\text { Abdominal } \\
\text { infection }\end{array}$} & Yes & $67(27.1)$ & $10(16.4)$ \\
\hline & No & $180(72.9)$ & 51 (83.6) \\
\hline \multirow[t]{2}{*}{ PBD } & No & $11(4.5)$ & $6(9.8)$ \\
\hline & Yes & $236(95.5)$ & $55(90.2)$ \\
\hline \multirow[t]{2}{*}{ Operation time } & $\geq 6 \mathrm{~h}$ & $233(94.3)$ & $60(98.4)$ \\
\hline & $<6 \mathrm{~h}$ & $14(5.7)$ & $1(1.6)$ \\
\hline \multirow[t]{2}{*}{ SDGE } & Yes & 27 (10.9) & $6(9.8)$ \\
\hline & No & $220(89.1)$ & 55 (90.2) \\
\hline
\end{tabular}

$P B D$ preoperative biliary drainage, $P G$ pancreaticogastrostomy, $P O$ Pancreatojejunostomy

The pathogenesis and mechanism of DGE after PD remains under investigation. Several factors are thought to be related to the occurrence of DGE: possible ischemia of pylorus and duodenum after surgery [29, 30]; gastricatony caused by denervation of pylorus ring or pylorospasm [31, 32]; gastric dysrhythmias caused by other complications [33, 34]; and the lack of gastrointestinal hormone [33]. More basic science studies are needed to determine the underlying mechanisms.

The anatomical configurations of reconstruction are thought to be important for gastric emptying. Kurahara et al. [35] found that the overall incidence of DGE in the antecolic group was significantly lower than that of the retrocolic group. However, another two RCTs found no difference between antecolic reconstruction and retrocolic reconstruction [36, 37]. Barakat et al. found that proximal Roux-en-y gastrojejunal anastomosis reduced the occurrence of DGE [38]. In the present study, all patients underwent antecolic reconstruction. Although the proportion of binding pancreaticogastrostomy was different between PPPD and PrPD groups, propensity score matching helped modify the possible confounding factors. Hanna et al. [8] found there was no difference between pancreaticogastrostomy and gastrojejunostomy.

In the present study, we found that the PPPD group had a significantly higher rate of postoperative pancreatic fistula and less blood loss. There were no differences in the occurrence rate of intra-abdominal infection, biliary leakage, postoperative bleeding, or mortality between the PPPD and PrPD groups. Though we did not analyze long-term survival or postoperative nutritional status, these studies revealed no differences in long-term survival or nutritional status between the PPPD and PrPD groups [1, 2, 12, 39, 40].

Although the occurrence of DGE was higher in the PPPD group than in the PrPD group, there were no differences in the length of hospital stay or hospital costs between the two groups in our study. We think the reasons for this are as follows. First, the patients were 


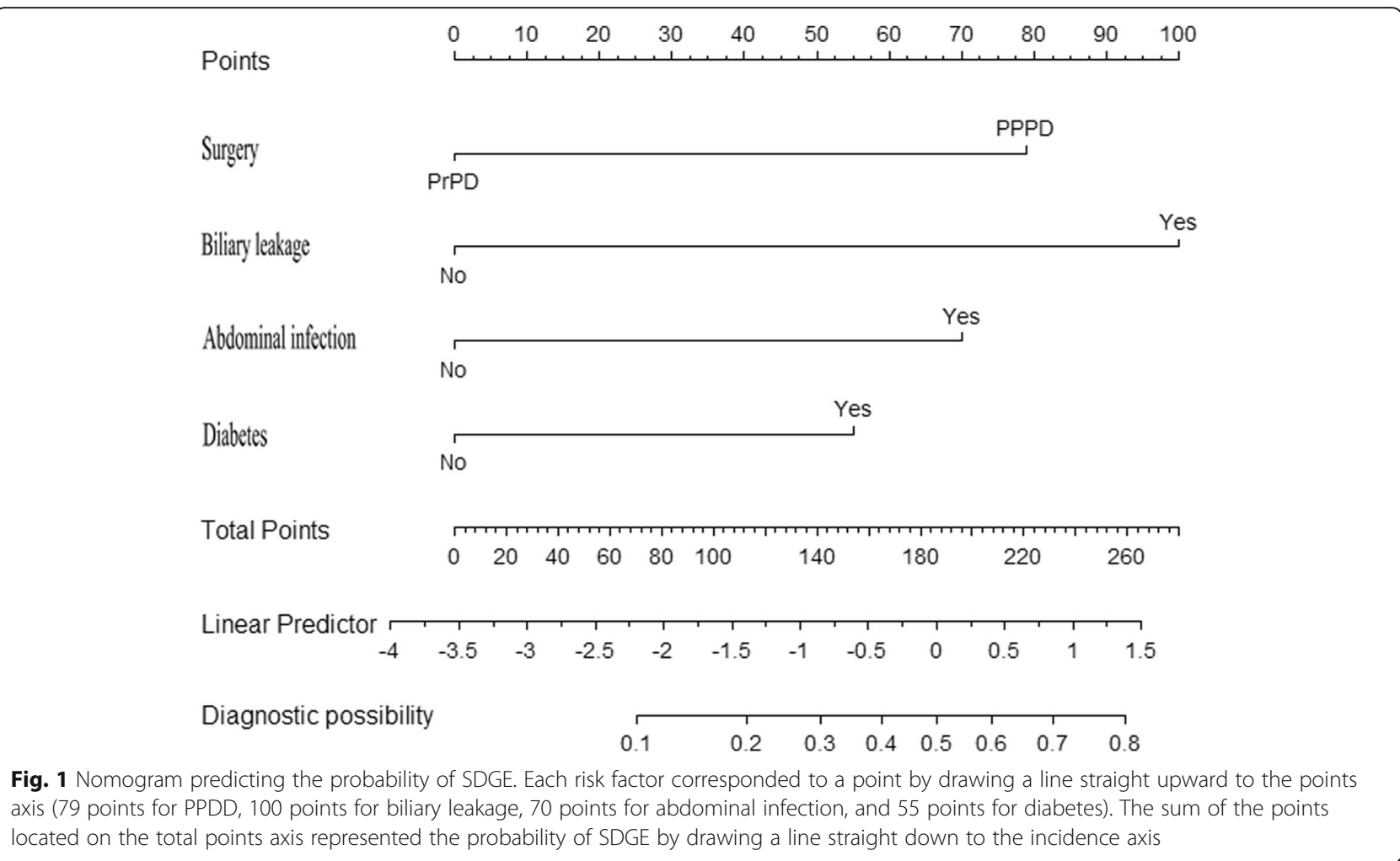

identified from 2009 to 2018, but we did not follow the contemporary ERAS type management of patients strictly from 2015. We usually engaged in a long observation to ensure the safety of patients in the hospital. Second, DGE is usually cured using conservative treatments, and the costs of hospitalization and nursing were low according to the special health care system in China. Therefore, the average hospital stay was quite long. In our opinion, it is reasonable to believe that DGE could be unpleasant for patients and could increase the length of hospital stay when the ERAS protocol is performed strictly.
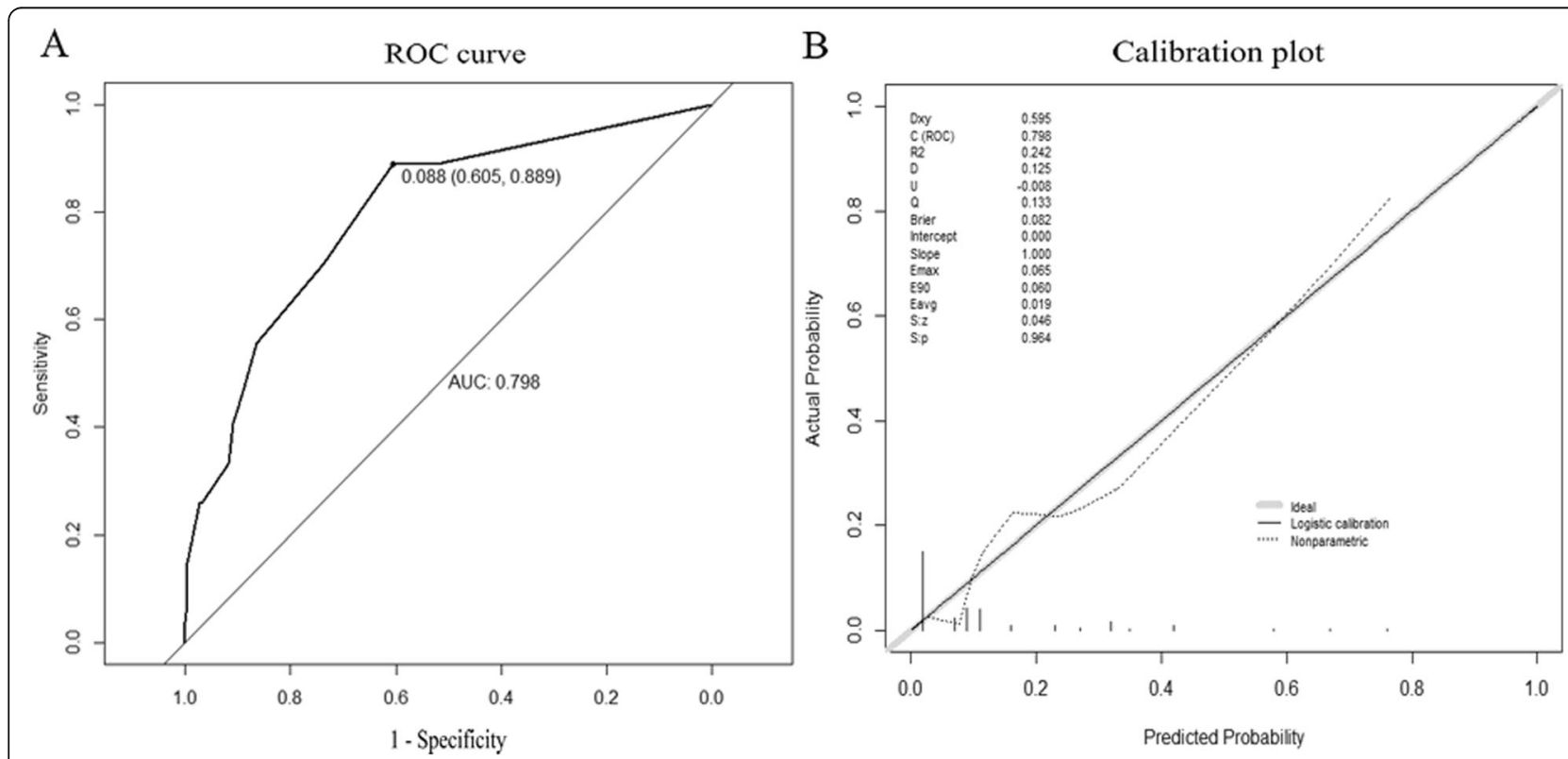

Fig. 2 discrimination and calibration of the predictive model according to the development set: $\mathbf{a}$. ROC curves; $\mathbf{b}$. calibration plot 
A randomized trial could provide a more reliable conclusion. The randomized method was used to prevent selective bias; the comparability of the two groups was better; and statistical results were more convincing. In our study, although the choice to perform PPPD or PrPD was determined by the surgeon at random rather than being related to the extent of tumor or some other factor, we did not use a strict randomization approach; therefore, there may have been subjective selection bias on the part of the surgeon. For this reason, propensity score matching was applied to build a randomized experiment-like situation and to decrease the influence of selection bias.

Our study has several advantages. First, to our knowledge, this is the first nomogram to predict the probability of SDGE after pancreaticoduodenectomy. SDGE usually requires an adjustment of clinical management. We also used internal validation to verify the good specificity and calibration of model; Second, propensity score matching was used to control for confounding biases to construct a randomized experiment-like situation; Third, this study had a large sample size, and we believe our experience adds meaningful data to the existing literature.

We acknowledge that this study also has several limitations. First, this study design was observational. Although many measured confounders were adjusted for by propensity score matching, the operation assignment was not randomized, and the results may be biased by other unmeasured factors; Second, we did not strictly follow the contemporary ERAS type management of patients. If we did not routinely place naso-gastric tubes or maintain the patients without enteral intake for 3 days, the differences between surgical methods may have changed. Further studies are needed to clarify this point; Third, our predictive model included postoperative complications as predictors of SDGE. When patients had these complications, their management would be more important than SDGE. This situation decreased the utility of the instruments. We will attempt to identify other pre-operative factors to predict SDGE in the future. Finally, we did not measure long-term survival because the patients with malignant tumors and benign lesions were combined.

\section{Conclusions}

PPPD increases the incidence of DGE. Biliary leakage, abdominal infection, and presence of diabetes were independent risk factors for SDGE. We created a simple nomogram for clinicians to make a preliminary estimation of the probability of SDGE. Further prospective studies are recommended to validate the model externally.

\section{Supplementary information}

Supplementary information accompanies this paper at https://doi.org/10. 1186/s12893-020-00809-5.

Additional file 1. Supplementary Table 1. The association between anastomotic pattern of the pancreas and other clinical characteristics
Additional file 2:. Supplementary Fig. 1 discrimination and calibration of the predictive model according to the validation set: A. ROC curves; B. Calibration plot

\section{Abbreviations}

PPPD: Pylorus-preserving pancreaticoduodenectomy; SSPPPDL: Subtotal stomach-preserving pancreaticoduodenectomy; PrPD: Pylorus-resecting pancreaticoduodenectomy; DGE: Delayed gastric emptying; SDGE: Severe delayed gastric emptying; ISGPS: The International Study Group of Pancreatic Surgery; OR: Odds ratio; Cl: Confidence interval; RCT: Randomized controlled trials; WBC: White blood cell; TB: Total bilirubin; PBD: Preoperative biliary drainage; PG: Pancreaticogastrostomy; PO: Pancreatojejunostomy; PS: Propensity scores; PTCD: Percutaneous transhepatic cholangial drainage; ENBD: Endoscopic nasobiliary drainage

\section{Acknowledgements}

We appreciate Professor Caide Lu for his operation for patients.

\section{Authors' contributions}

$X C$ and $W Y$ conceived and designed the study; $X C, C L, Y X$ and $M Z$ acquired and analyzed the data; $W Y, M Z$ and $X C$ interpreted the data and drafted the manuscript; All authors approved the final version to be published.

\section{Funding}

None.

\section{Availability of data and materials}

The datasets used and/or analysed during the current study are available from the corresponding author on reasonable request.

\section{Ethics approval and consent to participate}

This study was approved by the Ethics Committee of Ningbo medical center Lihuili Hospital. Written informed consent was obtained from all individual participants included in the study.

\section{Consent for publication}

Not applicable.

\section{Competing interests}

The authors declare no conflict of interests.

Received: 16 April 2020 Accepted: 29 June 2020

Published online: 09 July 2020

\section{References}

1. Kawai M, Tani M, Hirono S, Miyazawa M, Shimizu A, Uchiyama K, Yamaue H. Pylorus ring resection reduces delayed gastric emptying in patients undergoing pancreatoduodenectomy: a prospective, randomized, controlled trial of pylorus-resecting versus pylorus-preserving pancreatoduodenectomy. Ann Surg. 2011;253(3):495-501.

2. Matsumoto I, Shinzeki M, Asari S, Goto T, Shirakawa S, Ajiki T, Fukumoto T, Suzuki Y, Ku Y. A prospective randomized comparison between pylorusand subtotal stomach-preserving pancreatoduodenectomy on postoperative delayed gastric emptying occurrence and long-term nutritional status. J Surg Oncol. 2014;109(7):690-6.

3. Post M, Wrzesinski M, Klek R, Lubikowski J, Wojcicki M. Pancreatoduodenectomy with subtotal stomach-preserving and uncut roux reconstruction. Eur Surg Res. 2011;47(1):1-4.

4. Traverso LW, Longmire WP Jr. Preservation of the pylorus in pancreaticoduodenectomy. Surg Gynecol Obstet. 1978;146(6):959-62.

5. Jimenez RE, Fernandez-del Castillo C, Rattner DW, Chang Y, Warshaw AL. Outcome of pancreaticoduodenectomy with pylorus preservation or with antrectomy in the treatment of chronic pancreatitis. Ann Surg. 2000;231(3): 293-300.

6. Traverso LW, Longmire WP Jr. Preservation of the pylorus in pancreaticoduodenectomy a follow-up evaluation. Ann Surg. 1980;192(3): 306-10.

7. Akizuki E, Kimura Y, Nobuoka T, Imamura M, Nagayama M, Sonoda T, Hirata K. Reconsideration of postoperative oral intake tolerance after 
pancreaticoduodenectomy: prospective consecutive analysis of delayed gastric emptying according to the ISGPS definition and the amount of dietary intake. Ann Surg. 2009;249(6):986-94.

8. Hanna MM, Gadde R, Allen CJ, Meizoso JP, Sleeman D, Livingstone AS, Merchant N, Yakoub D. Delayed gastric emptying after pancreaticoduodenectomy. J Surg Res. 2016;202(2):380-8.

9. Xiong J, Szatmary P, Huang W, de la Iglesia-Garcia D, Nunes QM, Xia Q, Hu W, Sutton R, Liu X, Raraty MG. Enhanced recovery after surgery program in patients undergoing Pancreaticoduodenectomy: a PRISMA-compliant systematic review and meta-analysis. Medicine. 2016;95(18):e3497.

10. Zouros E, Liakakos T, Machairas A, Patapis P, Agalianos C, Dervenis C. Improvement of gastric emptying by enhanced recovery after pancreaticoduodenectomy. HBPD Int. 2016;15(2):198-208.

11. Wu W, Hong $X, F u$ L, Liu S, You L, Zhou L, Zhao Y. The effect of pylorus removal on delayed gastric emptying after pancreaticoduodenectomy: a meta-analysis of 2,599 patients. PLoS One. 2014;9(10):e108380.

12. Yang C, Wu HS, Chen XL, Wang CY, Gou SM, Xiao J, He ZQ, Chen QJ, Li YF. Pylorus-preserving versus pylorus-resecting pancreaticoduodenectomy for periampullary and pancreatic carcinoma: a meta-analysis. PLoS One. 2014; 9(3):e90316.

13. Peng SY, Wang JW, Hong DF, Liu YB, Wang YF. Binding pancreaticoenteric anastomosis: from binding pancreaticojejunostomy to binding pancreaticogastrostomy. Updat Surg. 2011;63(2):69-74.

14. Wente MN, Bassi C, Dervenis C, Fingerhut A, Gouma DJ, Izbicki JR, Neoptolemos JP, Padbury RT, Sarr MG, Traverso LW, et al. Delayed gastric emptying (DGE) after pancreatic surgery: a suggested definition by the international study Group of Pancreatic Surgery (ISGPS). Surgery. 2007; 142(5):761-8.

15. Bassi C, Dervenis C, Butturini G, Fingerhut A, Yeo C, Izbicki J, Neoptolemos J, Sarr M, Traverso W, Buchler M. Postoperative pancreatic fistula: an international study group (ISGPF) definition. Surgery. 2005;138(1):8-13.

16. Wente MN, Veit JA, Bassi C, Dervenis C, Fingerhut A, Gouma DJ, Izbicki JR, Neoptolemos JP, Padbury RT, Sarr MG, et al. Postpancreatectomy hemorrhage (PPH): an international study Group of Pancreatic Surgery (ISGPS) definition. Surgery. 2007;142(1):20-5.

17. $M$ K OJ G, RP, NN R, R A L C, ST F, Y Y, M C, M M et al. Bile leakage after hepatobiliary and pancreatic surgery: a definition and grading of severity by the International Study Group of Liver Surgery. Surgery. 2011;149(5):680-8.

18. D'Agostino RB Jr. Propensity score methods for bias reduction in the comparison of a treatment to a non-randomized control group. Stat Med. 1998;17(19):2265-81.

19. Jeong O, Jung MR, Kim GY, Kim HS, Ryu SY, Park YK. Comparison of shortterm surgical outcomes between laparoscopic and open total gastrectomy for gastric carcinoma: case-control study using propensity score matching method. J Am Coll Surg. 2013;216(2):184-91.

20. PC A: An introduction to propensity score methods for reducing the effects of confounding in observational studies. Multivar Behav Res 2011, 46(3): 399-424.

21. PC A: Some methods of propensity-score matching had superior performance to others: results of an empirical investigation and Monte Carlo simulations. Biom J 2009, 51(1):171-184.

22. X Z, X G, M Z. Nomograms Predict Survival Advantages of Gleason Score 3+ 4 Over 4+3 for Prostate Cancer: A SEER-Based Study. Front Oncol. 2019. 9(undefined):646.

23. Hashimoto $Y$, Traverso LW. Incidence of pancreatic anastomotic failure and delayed gastric emptying after pancreatoduodenectomy in 507 consecutive patients: use of a web-based calculator to improve homogeneity of definition. Surgery. 2010;147(4):503-15.

24. Hwang HK, Lee SH, Han DH, Choi SH, Kang CM, Lee WJ. Impact of Braun anastomosis on reducing delayed gastric emptying following pancreaticoduodenectomy: a prospective, randomized controlled trial. J Hepatobiliary Pancreat Sci. 2016;23(6):364-72.

25. Seiler CA, Wagner M, Bachmann T, Redaelli CA, Schmied B, Uhl W, Friess H, Buchler MW. Randomized clinical trial of pylorus-preserving duodenopancreatectomy versus classical Whipple resection-long term results. Br J Surg. 2005;92(5):547-56.

26. Tran KT, Smeenk HG, van Eijck CH, Kazemier G, Hop WC, Greve JW, Terpstra OT, Zijlstra JA, Klinkert P, Jeekel H. Pylorus preserving pancreaticoduodenectomy versus standard Whipple procedure: a prospective, randomized, multicenter analysis of 170 patients with pancreatic and periampullary tumors. Ann Surg. 2004;240(5):738-45.
27. Fujii T, Kanda M, Kodera Y, Nagai S, Sahin T, Hayashi M, Kanzaki A, Yamada $\mathrm{S}$, Sugimoto $\mathrm{H}$, Nomoto $\mathrm{S}$, et al. Preservation of the pyloric ring has little value in surgery for pancreatic head cancer: a comparative study comparing three surgical procedures. Ann Surg Oncol. 2012;19(1):176-83.

28. Nanashima A, Abo T, Sumida Y, Tobinaga S, Nonaka T, Takeshita H, Hidaka S, Sawai T, Yasutake T, Nagayasu T. Comparison of results between pyloruspreserving pancreaticoduodenectomy and subtotal stomach-preserving pancreaticoduodenectomy: report at a single cancer institute. Hepatogastroenterology. 2013;60(125):1182-8.

29. Ohwada S, Satoh Y, Kawate S, Yamada T, Kawamura O, Koyama T, Yoshimura S, Tomizawa N, Ogawa T, Morishita Y. Low-dose erythromycin reduces delayed gastric emptying and improves gastric motility after Billroth I pylorus-preserving pancreaticoduodenectomy. Ann Surg. 2001; 234(5):668-74

30. Park JS, Hwang HK, Kim JK, Cho SI, Yoon DS, Lee WJ, Chi HS. Clinical validation and risk factors for delayed gastric emptying based on the international study Group of Pancreatic Surgery (ISGPS) classification. Surgery. 2009;146(5):882-7.

31. Gauvin JM, Sarmiento JM, Sarr MG. Pylorus-preserving pancreaticoduodenectomy with complete preservation of the pyloroduodenal blood supply and innervation. Arch Surg (Chicago, III : 1960). 2003:138(11):1261-3.

32. Kim DK, Hindenburg AA, Sharma SK, Suk CH, Gress FG, Staszewski $H$, Grendell JH, Reed WP. Is pylorospasm a cause of delayed gastric emptying after pylorus-preserving pancreaticoduodenectomy? Ann Surg Oncol. 2005; 12(3):222-7.

33. Hocking MP, Harrison WD, Sninsky CA. Gastric dysrhythmias following pylorus-preserving pancreaticoduodenectomy. Possible mechanism for early delayed gastric emptying. Dig Dis Sci. 1990;35(10):1226-30.

34. Raty S, Sand J, Lantto E, Nordback I. Postoperative acute pancreatitis as a major determinant of postoperative delayed gastric emptying after pancreaticoduodenectomy. J Gastrointest Surg. 2006;10(8):1131-9.

35. Kurahara H, Shinchi H, Maemura K, Mataki Y, lino S, Sakoda M, Ueno S, Takao S, Natsugoe S. Delayed gastric emptying after pancreatoduodenectomy. J Surg Res. 2011;171(2):e187-92.

36. Eshuis WJ, van Eijck CH, Gerhards MF, Coene PP, de Hingh $\|_{\text {, Karsten TM, }}$ Bonsing BA, Gerritsen JJ, Bosscha K, Spillenaar Bilgen EJ, et al. Antecolic versus retrocolic route of the gastroenteric anastomosis after pancreatoduodenectomy: a randomized controlled trial. Ann Surg. 2014; 259(1):45-51.

37. Imamura N, Chijiiwa K, Ohuchida J, Hiyoshi M, Nagano M, Otani K, Kondo K. Prospective randomized clinical trial of a change in gastric emptying and nutritional status after a pylorus-preserving pancreaticoduodenectomy: comparison between an antecolic and a vertical retrocolic duodenojejunostomy. HPB. 2014;16(4):384-94.

38. Barakat O, Cagigas MN, Bozorgui S, Ozaki CF, Wood RP. Proximal roux-en-y Gastrojejunal anastomosis with pyloric ring resection improves gastric emptying after Pancreaticoduodenectomy. J Gastrointest Surg. 2016:20(5):914-23.

39. Srinarmwong C, Luechakiettisak P, Prasitvilai W. Standard whipple's operation versus pylorus preserving pancreaticoduodenectomy: a randomized controlled trial study. J Med Assoc Thail. 2008;91(5):693-8.

40. Lin PW, Shan YS, Lin YJ, Hung CJ. Pancreaticoduodenectomy for pancreatic head cancer: PPPD versus Whipple procedure. Hepato-gastroenterology. 2005;52(65):1601-4.

\section{Publisher's Note}

Springer Nature remains neutral with regard to jurisdictional claims in published maps and institutional affiliations. 